\title{
Effects of green-synthesized silver nanoparticles on lung cancer cells in vitro and grown as xenograft tumors in vivo
}

This article was published in the following Dove Press journal:

International Journal of Nanomedicine

4 May 2016

Number of times this article has been viewed

\author{
Yan He, ${ }^{1, *}$ Zhiyun Du, ${ }^{1, *}$ \\ Shijing Ma, 'Yue Liu, ${ }^{2}$ Dongli \\ Li,' Huarong Huang,' Sen \\ Jiang,' Shupeng Cheng,' \\ Wenjing Wu,' Kun Zhang,' \\ Xi Zheng ${ }^{1,2}$ \\ 'Allan H Conney Laboratory for \\ Anticancer Drug Research, School \\ of Chemical Engineering and Light \\ Industry, Guandong University of \\ Technology, Guangzhou, People's \\ Republic of China; ${ }^{2}$ Susan Lehman \\ Cullman Laboratory for Cancer \\ Research, Department of Chemical \\ Biology, Ernest Mario School of \\ Pharmacy, Rutgers, The State \\ University of New Jersey, Piscataway, \\ $\mathrm{NJ}$, USA \\ *These authors contributed equally \\ to this work
}

Correspondence: Xi Zheng Susan Lehman Cullman Laboratory for Cancer Research, Department of Chemical Biology, Ernest Mario School of Pharmacy, Rutgers, The State University of New Jersey, 164 Frelinghusen Road, Piscataway, NJ 08854, USA

Tel + I 7324453400 ext 233

Fax + I 7324450687

Email xizheng@pharmacy.rutgers.edu

Kun Zhang

Allan $\mathrm{H}$ Conney Laboratory for Anticancer Research, School of Chemical Engineering and Light Industry, Guangdong University of Technology, 100 Wai Huan West Road, Guangzhou Higher Education Mega Center,

Guangzhou 510006, People's Republic of China

Tel +862039323363

Fax +86203932 2231

Email kzhang@gdut.edu.cn

\begin{abstract}
Silver nanoparticles (AgNPs) have now been recognized as promising therapeutic molecules and are extending their use in cancer diagnosis and therapy. This study demonstrates for the first time the antitumor activity of green-synthesized AgNPs against lung cancer in vitro and in vivo. Cytotoxicity effect was explored on human lung cancer H1299 cells in vitro by MTT and trypan blue assays. Apoptosis was measured by morphological assessment, and nuclear factor- $\kappa \mathrm{B}(\mathrm{NF}-\kappa \mathrm{B})$ transcriptional activity was determined by a luciferase reporter gene assay. The expressions of phosphorylated stat 3 , bcl-2, survivin, and caspase- 3 were examined by Western blot analysis. AgNPs showed dose-dependent cytotoxicity and stimulation of apoptosis in H1299 cells. The effects on H1299 cells correlated well with the inhibition of NF- $\kappa B$ activity, a decrease in bcl-2, and an increase in caspase-3 and survivin expression. AgNPs significantly suppressed the H1299 tumor growth in a xenograft severe combined immunodeficient (SCID) mouse model. The results demonstrate the anticancer activities of AgNPs, suggesting that they may act as potential beneficial molecules in lung cancer chemoprevention and chemotherapy, especially for early-stage intervention.
\end{abstract}

Keywords: silver nanoparticles, antitumor, lung cancer, cytotoxicity, H1299

\section{Introduction}

Pharmaceutical application of nanomaterial is the most promising way for the generation of new fields in biomedical sciences. Among the silver nanoparticles (AgNPs), nanorization of silver is essentially one of the significant features for good conductivity, chemical stability, relative lower toxicity, and outstanding therapeutic potential, such as anti-inflammatory, antimicrobial, antifungal, anti-angiogenesis, antiplatelet, and anticancer activities. $^{1-4}$

A number of AgNPs have been developed by chemical, physical, and, recently improved, biological methods, among which green synthesis using plants or microorganisms is easier, more efficient, and ecofriendly. ${ }^{5,6}$ Many plant extracts have been regarded as potent natural reducing agents because of the presence of rich functional molecules, such as phenolic compounds with high antioxidant activity. ${ }^{7,8}$ Unlike other metal nanoparticles, AgNPs are nontoxic to human body at a lower dosage. ${ }^{9}$ Green synthesis of nanoparticles, with low range of toxicity, has become an attractive research area for increasing biomedical applications, such as in preparation of implantable biomaterial, molecular imaging, wound healing, and drug delivery. ${ }^{10-13}$

Especially, the applications of AgNPs have risen up in cancer diagnosis and treatment, ${ }^{14}$ not only as attractive targeted drug delivery vehicles or probes for early cancer screening ${ }^{15,16}$ but also as a promising therapeutic molecule by itself. AgNPs showed potential cytotoxicity 
against various cancer cells such as lung cancer A549 cells, ${ }^{17}$ breast cancer MCF-7 cells, ${ }^{18}$ colon cancer HT29 cells, ${ }^{19}$ cervical cancer HeLa cells, ${ }^{20}$ and Dalton's lymphoma ascites tumor. ${ }^{21}$ Hsin et al provided evidence for the mitochondrial pathway of apoptosis of AgNPs in NIH3T3 cells, which is mediated by a $R O S$ - and $J N K$-dependent mechanism. ${ }^{22}$ The previous study also showed that AgNPs possess anti-angiogenic effects due to the activation of PI3K/Akt signaling pathways. ${ }^{23} \mathrm{AgNPs}$ can selectively inhibit HeLa cells by caspase-3-mediated cell death and DNA damage. ${ }^{20}$ Yet, neither the underlying biochemical mechanisms nor the molecular triggers have been revealed. ${ }^{24}$ In general, the toxicity of AgNPs appears to be driven by the release of silver ions. AgNPs have a slower dissolution rate, leading to a continuous release of silver ions. It was reported that although AgNPs exhibited significant cytotoxicity against NSCLC A549 cells, they showed no cytotoxicity toward normal healthy peripheral lymphocytes (PLs). ${ }^{17}$ Greulich et al reported silver ions were more cytotoxic toward bacteria and human cells than AgNPs. ${ }^{25}$ The effects of AgNPs are distinct from those of silver ions in inducing neurotoxicity through oxidative stress in rat cerebral astrocytes. ${ }^{26}$ However, the toxicity effects and the underlying molecular mechanisms inside the human cells are not fully understood so far. The cellular events were unraveled in normal human lung fibroblast cells (IMR-90) and human glioblastoma cells (U251), and they indicated mitochondrial dysfunction and induction of reactive oxygen species (ROS), which in turn set off DNA damage and chromosomal aberrations, as the possible mechanisms. ${ }^{27}$ However, more studies on nanotoxicology should be carried out to trace the molecular mechanism underlying the bioaccumulation and toxicity of silver ions or AgNPs.

Reports on in vivo antitumor activity of AgNPs are also very limited. Sriram et al demonstrated the efficacy of biologically synthesized AgNPs as potential anticancer molecules that were shown to have a potent inhibitory activity on disease progression and a potent restorative effect in a Dalton's lymphoma ascites tumor-bearing mouse model. ${ }^{21}$ Intramuscular administration of silver and AgNPs significantly increased mice survival at day 35 (70\% and 60\% survival, respectively) in L5178Y-R tumor-bearing mouse model. ${ }^{28}$ This finding indicated that AgNPs showed anticancer activity in vivo. Though AgNPs as an antitumor agent can provide new opportunity for medical science, more studies are still needed to advance to clinical translation. When molecular mechanisms, signal pathways, and especially in vivo anticancer efficiency, are better understood, the applications of AgNPs can be expected to expand further.

In our previous study, we have shown that stable AgNPs with narrow size distribution can be prepared by using plants extracts as reducing agents. ${ }^{3}$ The present study was designed to explore the anticancer activities of our green-synthesized AgNPs in vitro and in vivo. These results further provide new approaches for treating lung cancer and other types of cancers by using silver-based nanoparticle therapies.

\section{Materials and methods Materials}

Silver nitrate $\left(\mathrm{AgNO}_{3}\right)$ and MTT were obtained from SigmaAldrich (St Louis, MO, USA). Dried longan (Dimocarpus longan Lour.) was purchased from the Panyu Chinese Herbal Medicine Market in Guangzhou. Prostate cancer VCaP, pancreas cancer BxPC-3, and lung cancer H1299 cells were obtained from American Type Culture Collection (ATCC, Rockville, MD, USA). RPMI-1640 culture medium, fetal bovine serum (FBS), L-glutamine, and penicillinstreptomycin were purchased from Thermo Fisher Scientific (Waltham, MA, USA). Trypan blue stain was obtained from Cambrex (Walkersville, MD, USA). Antibodies to $\beta$-actin, p-stat3, and survivin were purchased from EMD Millipore (Billerica, MA, USA) and antibodies to Bcl-2 from Santa Cruz Biotechnology Inc. (Dallas, TX, USA). Secondary antibodies were obtained from Santa Cruz Biotechnology. SuperSignal West Femto Luminol/Enhancer Solution was purchased from Thermo Fisher Scientific.

\section{Synthesis and characterization of AgNPs}

Dried and clean longan peel powder was used as the reducing and stabilizing agent during the synthesis of AgNPs which were produced as described in our previous work. ${ }^{7}$ Ten-gram peels were deeply immersed in $250 \mathrm{~mL}$ distilled water for 1 hour at $50^{\circ} \mathrm{C}$. The cooled filtrates were centrifuged at $3,000 \mathrm{rpm}$ for 5 minutes and then kept at $4^{\circ} \mathrm{C}$ for further use. Then, $50 \mathrm{~mL}$ aqueous solutions of $\mathrm{AgNO}_{3}(2.0 \mathrm{mM})$ were reacted with $50 \mathrm{~mL}$ of the extract solutions drop-wise by stirring at $80^{\circ} \mathrm{C}$ for 5 hours. Purified nanoparticles were examined by transmission electron microscope (TEM, H7100; Hitachi Ltd., Tokyo, Japan) and scanning electron microscope (SEM, QUANTA400; FEI, Hillsboro, OR, USA). The particle sizes and the morphologies were determined by taking photographs in several fields.

\section{Cell culture, MTT, and trypan blue assays}

Prostate cancer VCaP, pancreas cancer BxPC-3, and lung cancer H1299 cells were cultured in RPMI-1640 medium with $10 \% \mathrm{FBS}, 100 \mathrm{U} / \mathrm{mL}$ streptomycin, $100 \mathrm{U} /$ $\mathrm{mL}$ penicillin, and $300 \mu \mathrm{g} / \mathrm{mL}$ L-glutamine. AgNPs were dissolved in the medium. Cells were seeded at a density of $0.2 \times 10^{5}$ cells $/ \mathrm{mL}$ in 96 -well plates $(0.2 \mathrm{~mL} /$ well $)$ and incubated for 24 hours. Then the cells were treated with 
various concentrations of AgNPs $(2-30 \mu \mathrm{g} / \mathrm{mL})$ for 72 hours. MTT was added to the medium and incubated for 1 hour. After careful removal of the medium, dimethyl sulfoxide (DMSO, $0.1 \mathrm{~mL} /$ well) was added and incubated for 5 minutes under shaking. The absorbance at $570 \mathrm{~nm}$ was read on a microplate reader.

H1299 cell viability was further tested by the trypan blue exclusion assay. Approximately $2 \mathrm{~mL}$ cells were seeded at a density of $0.2 \times 10^{5}$ cells $/ \mathrm{mL}$ in the $35 \mathrm{~mm}$ dishes and cultured for 24 hours. Then the cells were treated with AgNPs $(2-30 \mu \mathrm{g} / \mathrm{mL})$ for 72 hours. The number of cells was determined by using a hemocytometer under a light microscope (Nikon Optiphot; Nikon Corporation, Tokyo, Japan) after mixing the cell suspension $(80 \mu \mathrm{L})$ with $0.4 \%$ trypan blue stain solution $(20 \mu \mathrm{L})$. The cells that did not absorb the dye were regarded as live cells, and the blue cells were counted as dead cells. This study was conducted with ethical permission from Rutgers University.

\section{Morphological assessment of apoptotic cells}

H1299 cells were placed onto the slides by means of cytospin technique, fixed with acetone/methanol $(\mathrm{v} / \mathrm{v}, 1: 1)$ for 10 minutes at room temperature, followed by 10 minutes of propidium iodide (1 $\mathrm{g} / \mathrm{mL})$ staining in phosphate-buffered saline (PBS), and then measured by a fluorescence microscope (Nikon Eclipse TE200; Nikon Corporation). Apoptotic cells were identified by the classical morphological features such as cell shrinkage, nuclear condensation, and formation of apoptotic bodies. A minimum of 200 cells per slide were evaluated in each sample and the percentage of apoptotic cells was determined.

\section{NF-KB-dependent reporter gene expression assay}

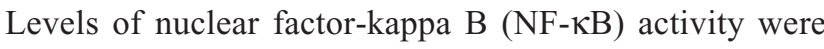
assessed by luciferase reporter assays, and $\mathrm{PC}-3 / \mathrm{N}$ cells were used in the study. PC-3/N cell is a kind of single table clone, that a NF-KB luciferase construct (\#CLS-013 L, SABiosciences, CA, USA) was stably transfected into PC-3 cells and PC-3/N was obtained. In brief, PC-3/N cells were treated with various concentrations of $\operatorname{AgNPs}(0,2,5,10,15$, and $20 \mu \mathrm{g} / \mathrm{mL})$ for 24 hours. Then the cells were washed with ice-cold PBS and harvested in $1 \times$ lysis buffer. After centrifugation, $10 \mu \mathrm{L}$ of the supernatant was measured for luciferase activity with a Turner Designs instrument luminometer. The NF- $\mathrm{kB}$-luciferase activity was monitored using the luciferase assay kits from Promega Corporation (Fitchburg, WI, USA). The luciferase activity was normalized against known protein concentrations and expressed as percentage of luciferase activity in the control cells.

\section{Western blot analysis}

The expressions of phosphorylated stat3, bcl-2, survivin, and caspase- 3 were examined by Western blot analysis according to the protocol followed in our laboratory. ${ }^{29}$ H1299 cells were seeded at a density of $1 \times 10^{5}$ cells $/ \mathrm{mL}$ and incubated for 24 hours. The cells were treated with $10 \mu \mathrm{g} / \mathrm{mL}$ of AgNPs. After treatment, the cells were washed with ice-cold PBS and lysed with $200 \mu \mathrm{L}$ of lysis buffer (1 mM phenylmethylsulfonyl fluoride, $100 \mu \mathrm{M}$ sodium orthovandate, $30 \mathrm{mM}$ sodium pyrophosphate, $50 \mathrm{mM}$ sodium chloride, $50 \mathrm{mM}$ sodium fluoride, $5 \mathrm{mM} \mathrm{ZnCl}_{2}$, 2 $\mathrm{mM}$ iodoacetic acid, $10 \mathrm{mM}$ Tris $-\mathrm{HCl}$, and $0.5 \%$ Triton $\mathrm{X}-100)$. Cell homogenates were centrifuged at $12,000 \times \mathrm{g}$ for 15 minutes at $4{ }^{\circ} \mathrm{C}$. The protein concentrations were determined by the Bio-Rad protein assay kit (Bio-Rad Laboratories Inc., Hercules, CA, USA). The $\beta$-actin protein was used as a loading control. Equal amounts of protein $(50 \mu \mathrm{g})$ were loaded on a Bio-Rad precast gel $(10 \%)$ and then transferred to a PVDF membrane. The membranes were subsequently incubated with stat3, bcl-2, survivin, or caspase- 3 primary antibodies (EMD Millipore) at $4^{\circ} \mathrm{C}$ overnight. After incubation, all membranes were washed with $0.05 \%$ Tween 20 Tris-buffered saline (TBST, 15 minutes) for four times, and then treated with secondary antibody (Santa Cruz Biotechnology) for 1 hour at room temperature. After washing the membranes again with TBST for four times, immunoreactivity was detected using thermo assay kit (SuperSignal West Femto Luminol/Enhancer Solution, Thermo Fisher Scientific) and analyzed by the Quantity One software (Bio-Rad Laboratories Inc.).

\section{Effect of intraperitoneal injection of AgNPs on HI299 tumors in SCID mouse model}

The studies were conducted on the female severe combined immunodeficient (SCID) mice (weighing $25 \pm 5 \mathrm{~g}$ ) from Taconic Farms (Germantown, NY, USA), which were housed in sterile filter-capped microisolator cages and provided with sterilized 5010 rodent diet and water. All animal experiments were performed under an Institutional Animal Care and Use Committee approved protocol. The animal studies were conducted under the permission of the Ethics Committees in Rutgers University. An initial toxicity test was carried out for a period of 22 days in normal SCID mice intraperitoneally (ip) injected with low, middle, and high doses $(5,10$, and $20 \mu \mathrm{g} / \mathrm{g}$ body weight/day) of AgNPs solutions.

H1299 cells $\left(2.0 \times 10^{6}\right.$ cells $/ 0.1 \mathrm{~mL}$ per mouse $)$ were first suspended in 50\% Matrigel (Collaborative Research, Bedford, MA, USA) in culture medium. Then the tumor cells 
were injected subcutaneously into the back of the mice. Mice (eight mice per group [Two groups \{vehicles and AgNPs for each]) received ip administration of vehicles $(5 \mu \mathrm{L} / \mathrm{g}$ body weight) or AgNPs (10 $\mu \mathrm{g} / \mathrm{g}$ body weight) three times a week. The vehicle consisted of a $0.5: 1: 10: 40: 48.5$ mixture of polysorbate 80 , benzyl alcohol, ethanol, propylene glycol, and water. Tumor size and body weight were determined. Tumor size was measured by determining the length and width (expressed as length $\times$ width in $\mathrm{cm}^{2}$ ). For study I, mice (tumor size approximately $0.2 \mathrm{~cm}^{2}$ ) were treated with AgNPs or vehicles 2 weeks after tumor transplantation and continued for 28 days. For study II, treatment with AgNPs or vehicles started 24 hours after tumor transplantation and continued for 36 days. All mice were sacrificed at the end of the study. The tumors were excised, fixed in phosphate-buffered formalin at room temperature for 48 hours, and then embedded in ethanol as previously described. ${ }^{29,30} \mathrm{~A}$ Mann-Whitney test and analysis of variance (ANOVA) were used for the comparison of effects between different groups.
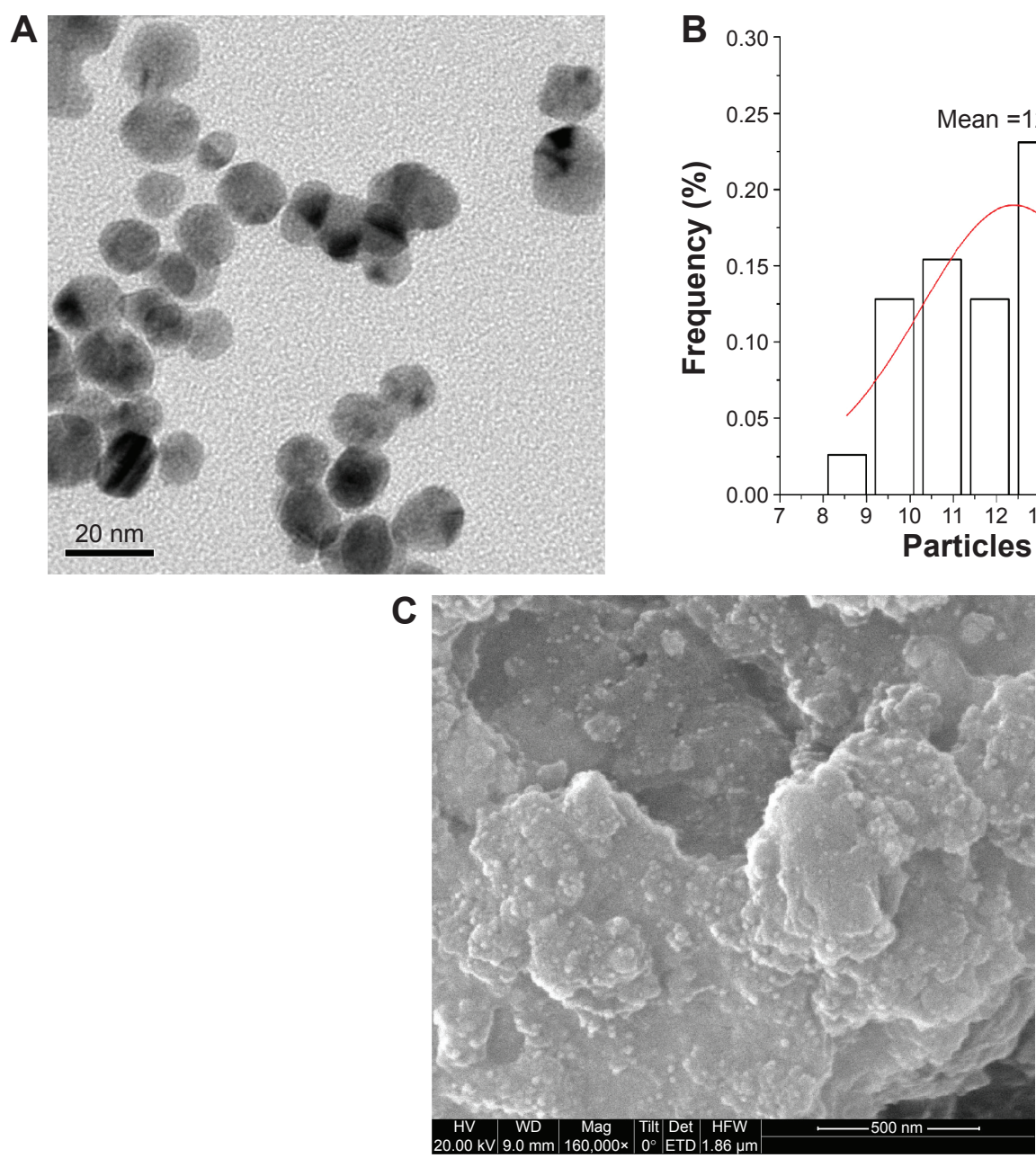

Figure I Morphology and particle size features of AgNPs.

Notes: TEM (A), particles size distribution (B), SEM (C) documentation of AgNPs morphology.

Abbreviations: TEM, transmission electron microscope; SEM, scanning electron microscope; AgNPs, silver nanoparticles.

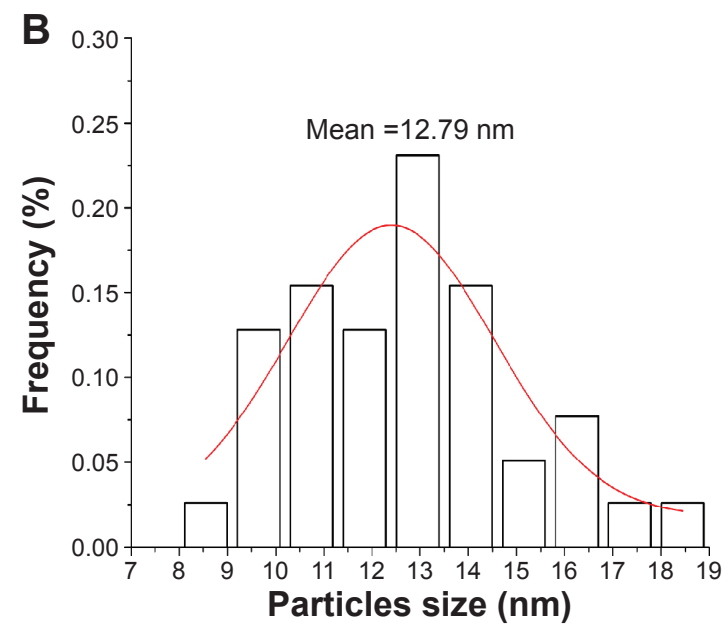

\section{Results \\ Characterization of AgNPs}

Through our early screening, we had found some edible plants, such as Chrysanthemum morifolium Ramat. ${ }^{7}$ Shaddock peel (Citrus maxima) and longan peel extracts are proved to be ecofriendly capping and reducing agents that can be used in the synthesis of AgNPs. In this study, AgNPs were green synthesized by using longan peels and were morphologically characterized by TEM and SEM. The images showed the purified nanoparticles were spherical in shape with a diameter range of $8-22 \mathrm{~nm}$, which is suitable for further study of anticancer effects (Figure 1).

\section{Inhibitory effects of AgNPs on HI299 cells, VCaP, and BxPC-3 cells}

In this study, the lung cancer cells are compared to the other two cancer cell types, ie, $\mathrm{VCaP}$ and $\mathrm{BxPC}-3$ cells. The $\mathrm{IC}_{50}$ values of AgNPs for H1299, VCaP, and BxPC-3 cells were 5.33 \pm 0.37 , $87.33 \pm 4.80$, and $38.9 \pm 2.10 \mu \mathrm{g} / \mathrm{mL}$, respectively, as determined 


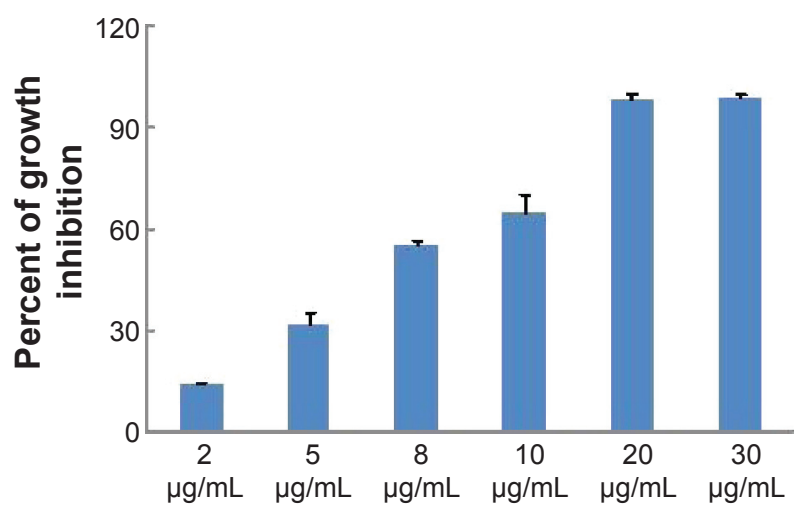

Figure 2 Effects of AgNPs on the growth of HI299 cells. Abbreviation: AgNPs, silver nanoparticles.

by MTT assay. AgNPs showed the best inhibitory effects on H1299 cells compared with the other two cancer cell types. Therefore, we further assessed the number of viable and dead H1299 cells using the trypan blue exclusion assay (Figure 2). Our cytotoxicity analysis shows a direct dose-response decrease in the number of viable H1299 cells. The percentage of viable cells decreased with increasing concentration of AgNPs.
Approximately, 50\% of H1299 cells died when treated with AgNPs at the concentrations between 5 and $8 \mu \mathrm{g} / \mathrm{mL}$.

\section{Stimulation of apoptosis in HI299 cells treated with AgNPs}

Morphological assessment was used to determine the effects of AgNPs on stimulating the apoptosis of H1299 cells. Treatment of $\mathrm{H} 1299$ cells with AgNPs at concentrations of 5, 10, and $20 \mu \mathrm{g} / \mathrm{mL}$ showed a dose-response apoptosis, resulting in $16.4 \% \pm 1.4 \%, 46.1 \% \pm 2.6 \%$, and $76.7 \% \pm 7.1 \%$ apoptotic cells, respectively (Figure 3 ).

\section{Effects of AgNPs on NF- $\kappa B$ transcriptional activity}

To elucidate the mechanisms by which AgNPs inhibited the growth and induced apoptosis in H1299 cells, we determined the effects of AgNPs on NF- $\mathrm{B}$ activation by a luciferase reporter gene expression assay. Treatment of PC-3/N cells with AgNPs resulted in dose-dependent decreases in NF- $\mathrm{KB}$ transcriptional activity (Figure 4).
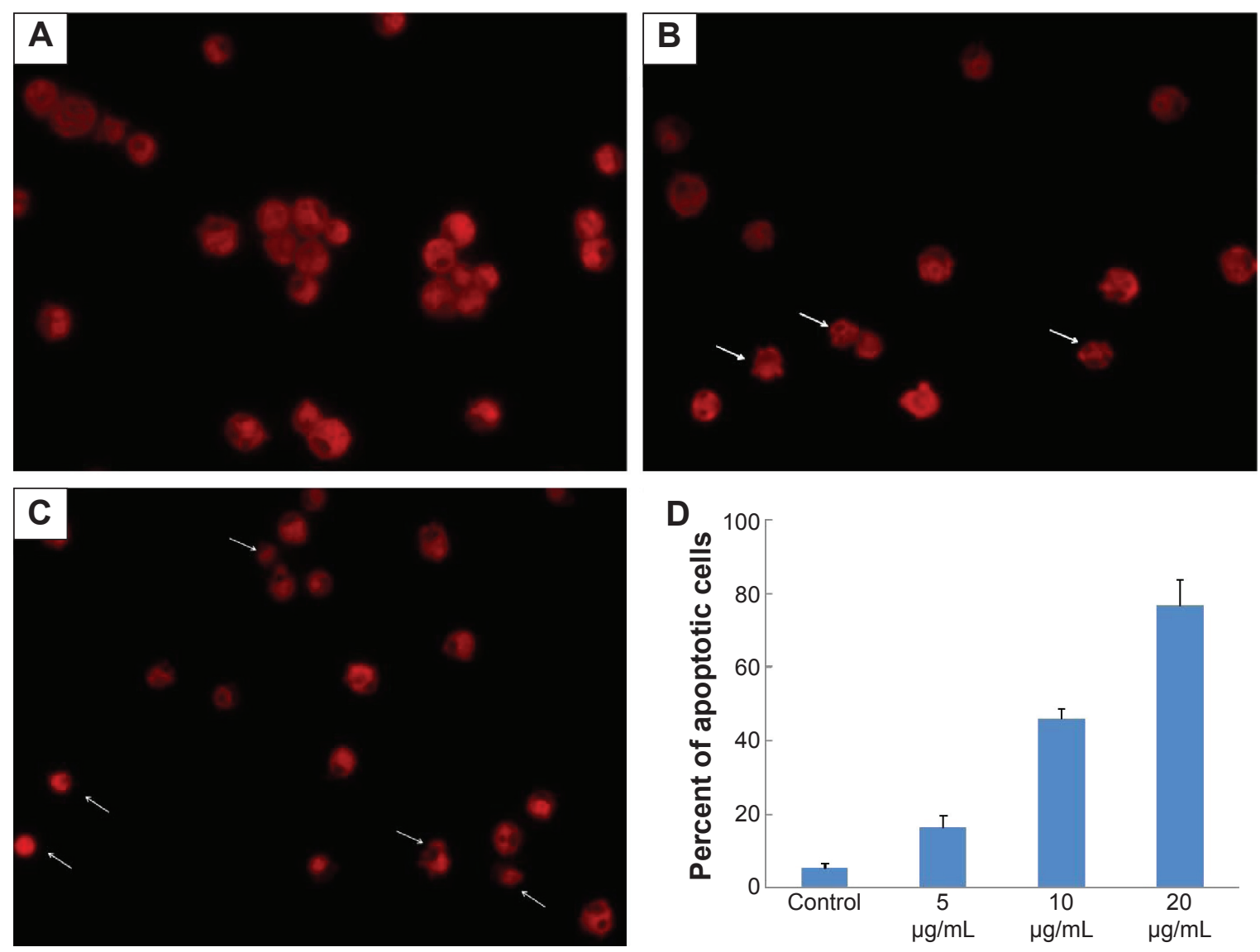

Figure 3 Effects of AgNPs on apoptosis of HI299 cells.

Notes: Representative pictures are shown in A (control), B (10 $\mu \mathrm{g} / \mathrm{mL}$ AgNPs induced), and C (20 $\mu \mathrm{g} / \mathrm{mL}$ AgNPs induced). (D) The percentage of apoptosis cells by different concentrations of AgNPs. The arrow is indicated as the apoptotic cells with the classical morphological features such as cell shrinkage, nuclear condensation, and formation of apoptotic bodies.

Abbreviation: AgNPs, silver nanoparticles. 


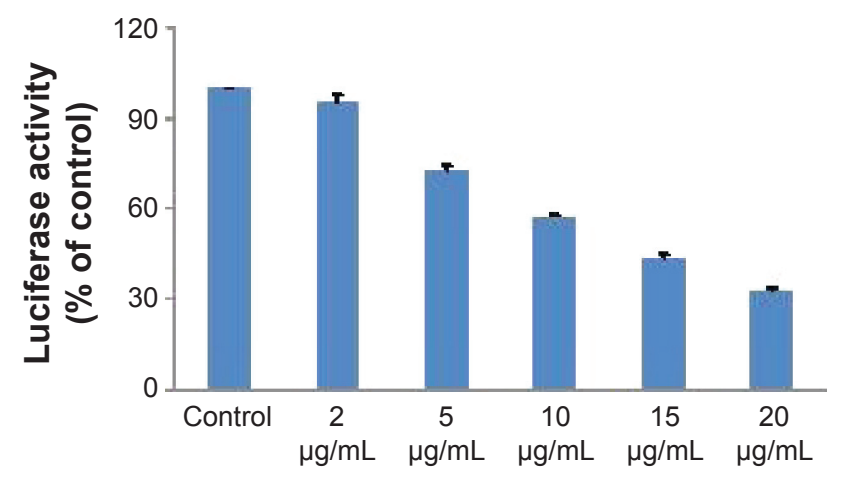

Figure 4 Inhibitory effects of AgNPs on NF-KB transcriptional activity in PC-3/N cells. Abbreviations: AgNPs, silver nanoparticles; NF- $\mathrm{B}$, nuclear factor-kappa $\mathrm{B}$.

Treatment of PC-3/N cells with $20 \mu \mathrm{g} / \mathrm{mL}$ AgNPs led to strong decreases in NF- $\kappa \mathrm{B}$ transcriptional activity. AgNPs at $10 \mu \mathrm{g} / \mathrm{mL}$ concentration had moderate inhibitory effects on NF- $\kappa \mathrm{B}$ transcriptional activity while $2 \mu \mathrm{g} / \mathrm{g}$ body weight concentration showed no effects.

\section{Effects of AgNPs on the levels of bcl-2, stat3, survivin, and caspase- 3}

The effects of AgNPs on the levels of phosphorylated bcl-2, stat3, survivin, and caspase- 3 in lung cancer cells were further determined by Western blotting at the concentration of $10 \mu \mathrm{g} / \mathrm{mL}$. The expressions were analyzed by optical density measurements and normalized for $\beta$-actin. As shown in Figure 5, the effects of AgNPs on H1299 cells included a decrease in bcl-2 and an increase in caspase- 3 and survivin levels. No changes were observed in stat 3 level.

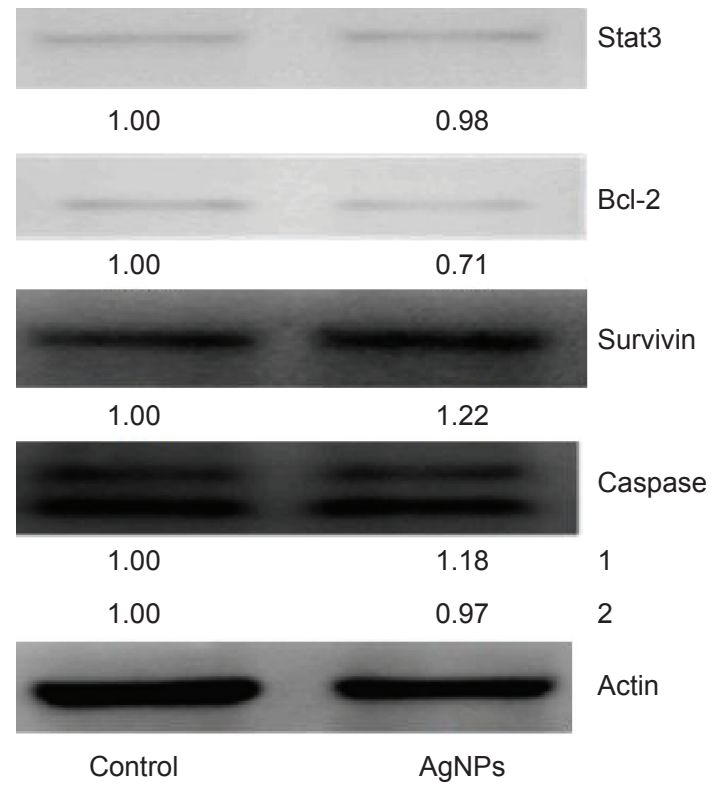

Figure 5 Effects of AgNPs on the expression of phosphorylated stat3, bcl-2, and caspase in $\mathrm{HI} 299$ cells.

Abbreviation: AgNPs, silver nanoparticles.

\section{Effects of AgNPs on HI299 tumors in SCID mice}

In the dose selection experiment, SICD mice were treated with 5, 10, and $20 \mu \mathrm{g} / \mathrm{g}$ body weight AgNPs for a period of 22 days. Percentage of initial body weight after last treatment was $94.2 \pm 2.8,94.9 \pm 1.7$, and $95.6 \pm 2.5$ (mean \pm standard error of the mean [SE]) for the groups treated with 5,10 and $20 \mu \mathrm{g} / \mathrm{g}$ AgNPs, respectively. Mice treated with high doses of AgNPs $(20 \mu \mathrm{g} / \mathrm{g})$ showed irritation with rectal prolapse and red ass. A moderate dose of $10 \mu \mathrm{g} / \mathrm{g}$ body weight/d was used for the subsequent experiments.

SCID mice received ip injections of AgNPs or vehicle daily 2 weeks (Figure 6) or 24 hours (Figure 7) after the inoculation of lung cancer H1299 cells. As shown in Figure 6, the average tumor size was similar in each group at the start of the experiment. The percentage of initial tumor size at 28 days was $8.78 \pm 0.42$ and $6.01 \pm 0.49$ (mean $\pm \mathrm{SE}$ ) for the vehicle group and the AgNPs-treated group, respectively. The percentage of initial body weight at 28 days was $96.5 \% \pm 2.5 \%$ and $93.4 \% \pm 2.2 \%$ for the control and the AgNPs group, respectively. Statistical analysis using Mann-Whitney test demonstrated the percentage of initial tumor size was significantly lower in the AgNPs-treated group compared with the control group at 28 days $(P=0.0104)$. After the injection of AgNPs, the development of lung tumors was slower than that of the control group, and the tumor size decreased noticeably on day 28 . The changes in body weight were similar for all the groups. As described in Figure 7, statistical analysis using ANOVA showed that the tumor size of AgNPs-treated group after 36 days was significantly smaller than that of the control $(P=0.0068)$ group. Tumor size in mice after 36 days of treatment was $1.13 \pm 0.21 \mathrm{~mm}^{2}$ for the control group and $0.49 \pm 0.07 \mathrm{~mm}^{2}$ for the AgNPs-treated group. The study displayed that the AgNPs had a strong effect in slowing down the lung tumor growth compared with the control group. The percentage of initial body weight after 36 days was $100.2 \% \pm 1.0 \%$ and $98.7 \% \pm 0.9 \%$ for the vehicle group and the AgNPs group, respectively. The differences in the percentage of initial body weight were not statistically significant between the two groups. In this study, we have shown that ip injection of AgNPs had a significant difference in preventing the tumor growth as opposed to the control group, which implied that AgNPs exhibited anticancer effects against non-small-cell lung cancer (NSCLC) in vivo. Further researches should be carried out for the potential use of AgNPs in the treatment of NSCLCs.

\section{Discussion}

The size of AgNPs obtained in this study is desirable to demonstrate anticancer effects and toxicity. ${ }^{31,32}$ Numerous factors, including surfactant, reactants, and reaction conditions, play 
A

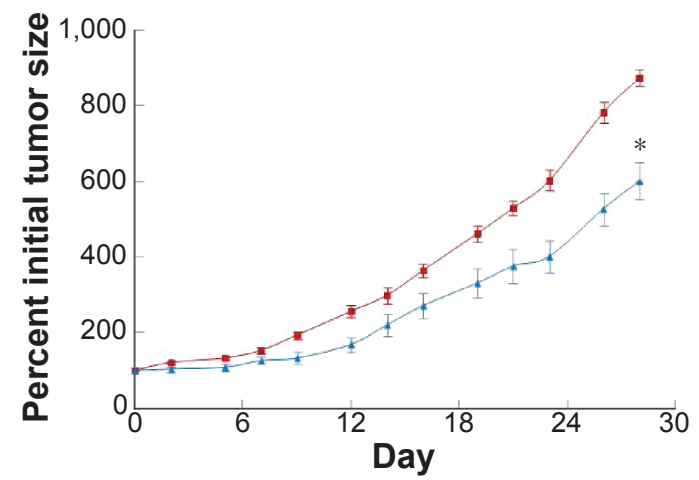

B

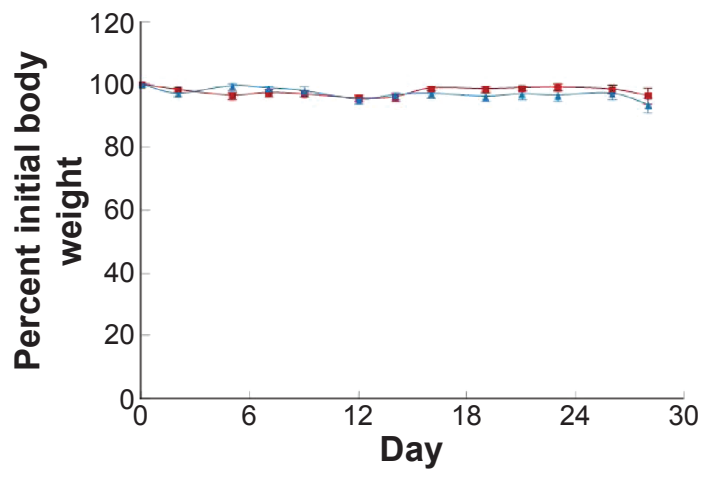

- Control $\_$AgNPs $(5 \mu \mathrm{g} / \mathrm{g})$

Figure 6 Effects of ip administration of AgNPs on the progression and growth of HI 299 tumors.

Notes: (A) Growth curve of HI299 tumors in each group. Each value is mean \pm SE from eight mice. (B) Individual body weight of mice after treatment for 28 days. $* \mathrm{P}<0.05$.

Abbreviations: AgNPs, silver nanoparticles; ip, intraperitoneal.

an important role in determining the size of AgNPs. ${ }^{33,34} \mathrm{~A}$ size-controlled targeting strategy could prove effective for AgNPs in cancer treatment which is based on the different pore sizes the between cancer cells and normal cells. ${ }^{5}$ The AgNPs with smaller size have a stronger penetration ability and greater toxicity, while the larger size AgNPs reduce the targeting efficacy by not binding with the receptors. We successfully green-synthesized uniform AgNPs with sizes in the range of 8-22 $\mathrm{nm}$ by using longan peel extracts (Figure 1).

The AgNPs were further investigated for their cytotoxic activity in lung cancer cells. NSCLC accounts for $\sim 85 \%$ of all lung cancers, which is the leading cause of tumorrelated death worldwide, and highlights the need for even more effective treatment strategies. ${ }^{35}$ It has become widely recognized that AgNps can be used as carriers or antimicrobial agents, such as AgNps-embedded membrane system or microbicidal tissue paper which exhibits antibacterial activity. ${ }^{36,37}$ Another exciting field that needs attention is their anticancer property, which enables them to be directly used as a drug. Silver is now extending its use as a latent therapeutic agent in anticancer field. Many attempts that were made to use AgNPs as antitumor molecules gave meaningful and positive results. Lung cancer is a devastating disease that progresses rapidly with a high degree of malignancy and short survival time. The disease progresses from early to advanced stages within a year of diagnosis. Patients with lung cancer generally have lower survival rate than other types of cancer, such as the pancreas, prostate, colon, and breast. In vitro experiments were performed in this study to compare the anticancer effects of AgNPs on the lung cancer cells with those on the pancreas and prostate cancer cells. AgNPs showed potent inhibitory effects on the H1299 cells

B

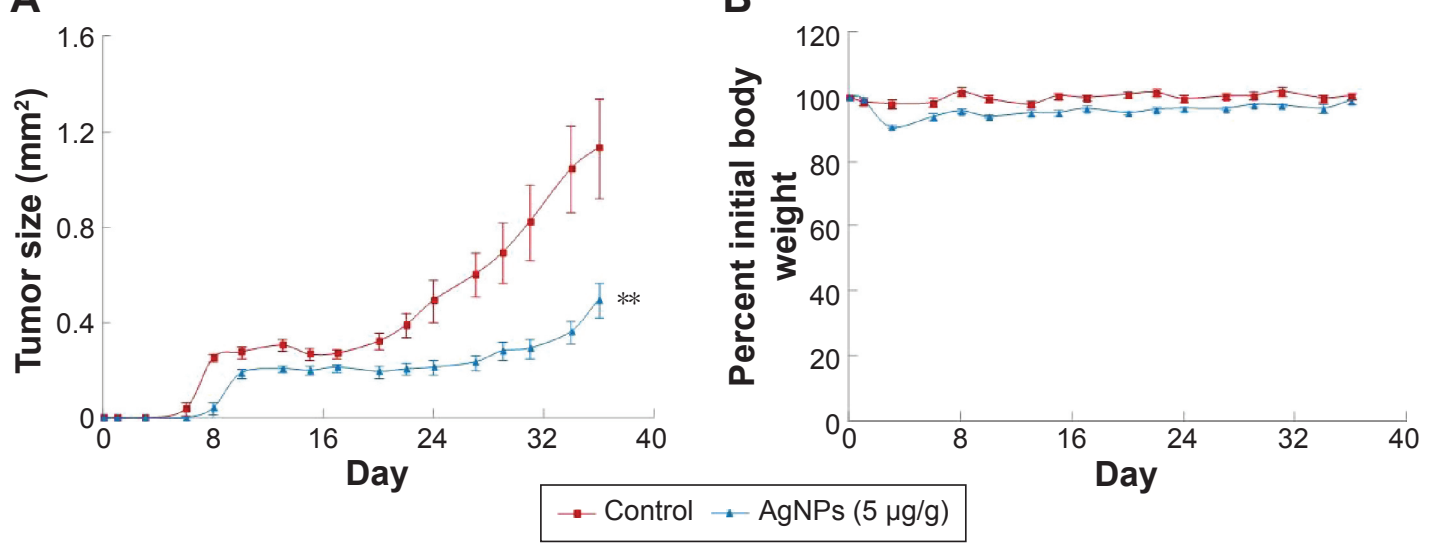

Figure 7 Effects of ip administration of AgNPs on the development and growth of $\mathrm{H} 1299$ tumors.

Notes: (A) Growth curve of HI299 tumors in each group. Each value represents mean \pm SE from nine mice. (B) Individual body weight of mice after treatment for 36 days. $* * P<0.01$.

Abbreviations: AgNPs, silver nanoparticles; ip, intraperitoneal. 
with $\mathrm{IC}_{50}$ value of $5.33 \pm 0.37 \mu \mathrm{g} / \mathrm{mL}$, but less effect on the $\mathrm{VCaP}$ and BxPC-3 cells. One possible reason for the potent inhibitory effects of AgNPs on the lung cancer cells might be due to the characteristics of this cancer, ie, the cells of this cancer show a higher rate of metabolism, rapid cell division, and consequently exhibit enhanced AgNPs internalization, leading to a higher cell death rate. Researchers demonstrated the intracellular release of silver ions in HeLa and A549 cells after nanoparticle internalization, showing that in situ particle degradation is promoted by the acidic lysosomal environment and a cause-effect relationship between ions and cell death. ${ }^{31}$ Cellular internalization of AgNPs provided the basis for the their cytotoxic activities. ${ }^{38}$ However, more basic issues concerning the metabolism rate and internalization characteristics of AgNPs after internalization are not clearly delineated till today. More research is needed to elucidate the underlying biological mechanisms which, in turn, can lead to effective preventative measures or treatments for lung cancer.

The mechanism by which the AgNPs evade the cancer cells remains unclear. Regulation of apoptosis and NF- $\kappa \mathrm{B}$ activity has been considered as a promising target for lung cancer therapies. Most anticancer drugs induce apoptosis in target cells. Activated NF- $\kappa \mathrm{B}$ is a key regulator of apoptosis in lung cancer progression by the transcriptional regulation of responsive genes. ${ }^{39}$ Remarkably, this apoptosis was often related with a suppression of the expression of antiapoptotic bcl-2 family proteins, which are also an important cellular regulators in the apoptosis of the lung cancer cells. The suppression of bcl-2 pathways is one of the mechanisms by which activation of NF- $\mathrm{KB}$ induces cancer cell death. ${ }^{40,41}$ Thus, it is an attractive and potential strategy to restore the normal apoptotic process in these cells or make these cells more susceptible for conventional therapy or prevention by inhibition of the overexpressed bcl-2 protein in tumor cells. As shown in Figures 3 and 4, treatment of H1299 cells with AgNPs induced the apoptosis in correlation with dose-dependent decreases of NF- $\kappa \mathrm{B}$ transcriptional activities. The effects of AgNPs on H1299 cells were associated with a suppression of bcl-2 proteins, resulting in the apoptotic cell death (Figure 5).

However, the evidence for anticancer effects in vivo is still insufficient. The lung cancer is especially more aggressive and difficult to cure when tumors grow large and metasta size. In our studies in vivo, we observed that lung cancer developed fast, and ulcers were observed in most of the mice 28 days after the formation of tumors with size approximately $0.2 \mathrm{~cm}^{2}$ in the control group. Figure 6 shows AgNPs could slow down the growth of lung tumors with statistical difference at day 28. It could be beneficial if the immunodeficient mice received AgNPs treatment immediately after the tumor cell inoculation. There was significant difference in the tumor size between the vehicle-treated group and AgNPs-treated group at 36 days, as shown in Figure 7. AgNPs could effectively inhibit and slow down the growth of lung tumors in 36 days. It implied that AgNPs are effective candidates for lung cancer chemoprevention than chemotherapy in vivo. The results suggested our synthesized AgNPs possess great selectivity toward the NSCLC and displayed a potential application for cancer chemoprevention and chemotherapy, especially for early-stage treatment. The study demonstrated the potential function of AgNPs as a promising way in the management of NSCLC.

\section{Conclusion}

The present study demonstrated that AgNPs showed a strong inhibitory effect on the growth of NSCLC cells (H1299) associated with their effects on NF- $\mathrm{B}$, bcl-2, caspase-3, and survivin. In a mouse H1299 xenograft tumor model, injection of mice with AgNPs potently suppressed the growth of H1299 tumors in SCID mice. AgNPs are better candidates for lung cancer chemoprevention than chemotherapy in vivo. Further researches should be carried out for the potential use of AgNPs in the treatment of NSCLCs.

\section{Acknowledgments}

The present study was supported by grants from the Postdoctoral Science Foundation China (2013M540649), the International Collaboration Project from Guangzhou Science \& Technology (2013J4500014), and Allan H Conney Leadership Grant from Guangdong Province.

\section{Disclosure}

The authors report no conflicts of interest in this work.

\section{References}

1. Austin LA, Mackey MA, Dreaden EC, El-Sayed MA. The optical, photothermal, and facile surface chemical properties of gold and silver nanoparticles in biodiagnostics, therapy, and drug delivery. Arch Toxicol. 2014;88(7):1391-1417.

2. Vaidyanathan R, Kalishwaralal K, Gopalram S, Gurunathan S. Nanosilver - the burgeoning therapeutic molecule and its green synthesis. Biotechnol Adv. 2009;27(6):924-937.

3. Dar MA, Ingle A, Rai M. Enhanced antimicrobial activity of silver nanoparticles synthesized by Cryphonectria sp. evaluated singly and in combination with antibiotics. Nanomedicine. 2013;9(1):105-110.

4. Tolaymat TM, El Badawy AM, Genaidy A, Scheckel KG, Luxton TP, Suidan M. An evidence-based environmental perspective of manufactured silver nanoparticle in syntheses and applications: a systematic review and critical appraisal of peer-reviewed scientific papers. Sci Total Environ. 2010;408(5):999-1006.

5. Schluesener JK, Schluesener HJ. Nanosilver: application and novel aspects of toxicology. Arch Toxicol. 2013;87(4):569-576.

6. Poulose S, Panda T, Nair PP, Théodore T. Biosynthesis of silver nanoparticles. J Nanosci Nanotechnol. 2014;14(2):2038-2049. 
7. He Y, Du Z, Lv H, et al. Green synthesis of silver nanoparticles by Chrysanthemum morifolium Ramat. extract and their application in clinical ultrasound gel. Int J Nanomed. 2013;8:1809-1815.

8. Harshiny M, Matheswaran M, Arthanareeswaran G, Kumaran S, Rajasree S. Enhancement of antibacterial properties of silver nanoparticles-ceftriaxone conjugate through Mukia maderaspatana leaf extract mediated synthesis. Ecotoxicol Environ Saf. 2015;121:135-141.

9. Stensberg MC, Wei Q, McLamore ES, Porterfield DM, Wei A, Sepúlveda MS. Toxicological studies on silver nanoparticles: challenges and opportunities in assessment, monitoring and imaging. Nanomedicine. 2011;6(5):879-898.

10. Chaloupka K, Malam Y, Seifalian AM. Nanosilver as a new generation of nanoproduct in biomedical applications. Trends Biotechnol. 2010; 28(11):580-588

11. Kohl Y, Kaiser C, Bost W, et al. Preparation and biological evaluation of multifunctional PLGA nanoparticles designed for photoacoustic imaging. Nanomedicine. 2011;7(2):228-237.

12. Tian J, Wong KK, Ho CM, et al. Topical delivery of silver nanoparticles promotes wound healing. Chem Med Chem. 2007;2(1):129-136.

13. dos Santos CA, Seckler MM, Ingle AP, et al. Silver nanoparticles: therapeutical uses, toxicity, and safety issues. J Pharm Sci. 2014;103(7): 1931-1944.

14. Ong C, Lim JZ, Ng CT, Li JJ, Yung LY, Bay BH. Silver nanoparticles in cancer: therapeutic efficacy and toxicity. Curr Med Chem. 2013; 20(6):772-781.

15. Locatelli E, Naddaka M, Uboldi C, et al. Targeted delivery of silver nanoparticles and alisertib: in vitro and in vivo synergistic effect against glioblastoma. Nanomedicine. 2014;9(6):839-849.

16. Wei X, Li H, Li Z, et al. Metal-enhanced fluorescent probes based on silver nanoparticles and its application in IgE detection. Anal Bioanal Chem. 2012;402(3):1057-1063.

17. Gengan RM, Anand K, Phulukdaree A, Chuturgoon A. A549 lung cell line activity of biosynthesized silver nanoparticles using Albizia adianthifolia leaf. Colloids and Surfaces B Biointerfaces. 2013;105(4):87-91.

18. Jeyaraj M, Sathishkumar G, Sivanandhan G, et al. Biogenic silver nanoparticles for cancer treatment: an experimental report. Colloids Surf B Biointerfaces. 2013;106(2):86-92.

19. Sanpui P, Chattopadhyay A, Ghosh SS. Induction of apoptosis in cancer cells at low silver nanoparticle concentrations using chitosan nanocarrier. ACS Appl Mater Interfaces. 2011;3(2):218-228.

20. Jeyaraj M, Rajesh M, Arun R, et al. An investigation on the cytotoxicity and caspase-3-mediated apoptotic effect of biologically synthesized silver nanoparticles using Podophyllum hexandrum on human cervical carcinoma cells. Colloids Surf B Biointerfaces. 2013;102(1):708-717.

21. Sriram MI, Kanth SB, Kalishwaralal K, Gurunathan S. Antitumor activity of silver nanoparticles in Dalton's lymphoma ascites tumor model. Int J Nanomed. 2010;5(1):753-762.

22. Hsin YH, Chen CF, Huang S, Shih TS, Lai PS, Chueh PJ. The apoptotic effect of nanosilver is mediated by a ROS- and JNK-dependent mechanism involving the mitochondrial pathway in NIH3T3 cells. Toxicol Lett. 2008;179(3):130-139.

23. Gurunathan S, Lee KJ, Kalishwaralal K, Sheikpranbabu S, Vaidyanathan R, Eom SH. Antiangiogenic properties of silver nanoparticles. Biomaterials. 2009;30(31):6341-6350.

24. De Lima R, Seabra AB, Durán N. Silver nanoparticles: a brief review of cytotoxicity and genotoxicity of chemically and biogenically synthesized nanoparticles. J Appl Toxicol. 2012;32(11):867-879.

International Journal of Nanomedicine

\section{Publish your work in this journal}

The International Journal of Nanomedicine is an international, peerreviewed journal focusing on the application of nanotechnology in diagnostics, therapeutics, and drug delivery systems throughout the biomedical field. This journal is indexed on PubMed Central, MedLine, CAS, SciSearch $®$, Current Contents $\AA /$ Clinical Medicine,
25. Greulich C, Braun D, Peetsch A, et al. The toxic effect of silver ions and silver nanoparticles towards bacteria and human cells occurs in the same concentration range. RSC Advances. 2012;2(17):6981-6987.

26. Sun C, Yin N, Wen R, et al. Silver nanoparticles induced neurotoxicity through oxidative stress in rat cerebral astrocytes is distinct from the effects of silver ions. Neurotoxicology. 2016;52:210-221.

27. AshaRani PV, Mun GLK, Hande MP, Valiyaveettil S. Cytotoxicity and genotoxicity of silver nanoparticles in human cells. Acs Nano. 2009; 3(2):279-290.

28. José HL, Ricardo GF, Patricia TG, Enriqueta MC, Reyes TG, Cristina RP. In vivo antitumor activity of metal silver and silver nanoparticles in the L5178Y-R murine lymphoma model. Br J Med Med Res. 2013;3(4):1308-1316.

29. Zheng X, Chang RL, Cui XX, et al. Effects of 12-O-tetradecanoylphorbol13-acetate (TPA) in combination with paclitaxel (Taxol) on prostate cancer LNCaP cells cultured in vitro or grown as xenograft tumors in immunodeficient mice. Clin Cancer Res. 2006;12(11 Pt 1):3444-3451.

30. Zhou DY, Ding N, Van Doren J, et al. Effects of curcumin analogues for inhibiting human prostate cancer cells and the growth of human PC-3 prostate xenografts in immunodeficient mice. Biol Pharm Bull. 2014;37(6):1029-1034.

31. De Matteis V, Malvindi MA, Galeone A, et al. Negligible particlespecific toxicity mechanism of silver nanoparticles: the role of $\mathrm{Ag}+$ ion release in the cytosol. Nanomedicine. 2015;11(3):731-739.

32. Li L, Sun J, Li X, et al. Controllable synthesis of monodispersed silver nanoparticles as standards for quantitative assessment of their cytotoxicity. Biomaterials. 2012;33(6):1714-1721.

33. Park MV, Neigh AM, Vermeulen JP, et al. The effect of particle size on the cytotoxicity, inflammation, developmental toxicity and genotoxicity of silver nanoparticles. Biomaterials. 2011;32(36):9810-9817.

34. Singh S, Nalwa HS. Nanotechnology and health safety-toxicity and risk assessments of nanostructured materials on human health. J Nanosci Nanotechnol. 2007;7(9):3048-3070.

35. Saintigny $P$, Burger JA. Recent advances in non-small cell lung cancer biology and clinical management. Discov Med. 2012;13(71):287-297.

36. Kiruba Daniel SCG, Abirami J, Kumaran S, Sivakumar M. Microbicidal tissue paper using green synthesized silver nanoparticles. Curr Nanosci. 2015;11(1):64-68.

37. Kiruba Daniel SCG, Nazeema Banu B, Harshiny M, et al. Ipomea carnea-based silver nanoparticle synthesis for antibacterial activity against selected human pathogens. J Exp Nanosci. 2014;9(2):197-209.

38. Söderstjerna E, Bauer P, Cedervall T, Abdshill H, Johansson F, Johansson UE. Silver and gold nanoparticles exposure to in vitro cultured retina - studies on nanoparticle internalization, apoptosis, oxidative stress, glial- and microglial activity. PLoS One. 2014;9(8):e105359.

39. Stẹpkowski TM, Brzóska K, Kruszewski M. Silver nanoparticles induced changes in the expression of NF- $\kappa \mathrm{B}$ related genes are cell type specific and related to the basal activity of NF-кB. Toxicol In Vitro. 2014; 28(4):473-478.

40. Matsushita H, Morishita R, Nata T, et al. Hypoxia-induced endothelial apoptosis through nuclear factor-kappaB (NF-kappaB)-mediated bcl-2 suppression: in vivo evidence of the importance of NF-kappaB in endothelial cell regulation. Circ Res. 2000;86(9):974-981.

41. Jin HO, Seo SK, Woo SH, et al. A combination of sulindac and arsenic trioxide synergistically induces apoptosis in human lung cancer H1299 cells via c-Jun NH2-terminal kinase-dependent Bcl-xL phosphorylation. Lung Cancer. 2008;61(1):317-327. 